\title{
The Advancement of Science, and Its Burdens
}

\section{Citation}

Holton, Gerald. 1986. The Advancement of Science, and Its Burdens. Daedalus 115 (3): 75 , 77-104.

\section{Published Version}

https://www.jstor.org/stable/20025062?seq=1\#metadata_info_tab_contents

\section{Permanent link}

http://nrs.harvard.edu/urn-3:HUL.InstRepos:40508262

\section{Terms of Use}

This article was downloaded from Harvard University's DASH repository, and is made available under the terms and conditions applicable to Other Posted Material, as set forth at http:// nrs.harvard.edu/urn-3:HUL.InstRepos:dash.current.terms-of-use\#LAA

\section{Share Your Story}

The Harvard community has made this article openly available.

Please share how this access benefits you. Submit a story.

Accessibility 


\section{The Advancement of Science, and Its Burdens ${ }^{1}$}

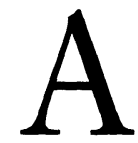

$S$ THE FIRST OF THE JEFFERSON LECTURERS to have been brought up in science, one of my themes must be the nature of scientific understanding; and as the first speaker in the series to have come to this country in search of a haven of liberty, my other main theme necessarily concerns the conditions that strengthen or threaten democracy-the more so as the award directs the occasion be "in the service of the general public interest," bringing to bear the speaker's experiences "upon aspects of contemporary culture and matters of broad public concern."

Thomas Jefferson himself, I believe, would have had no difficulty discerning the connection between the two themes, between the power of science and the condition of society. He saw a double purpose for the pursuit of science: the advancement both of knowledge and of "the freedom and happiness of man." From the many examples that would serve as practical illustrations of Jefferson's twin goals, let me select his protracted study of the design for the humble plough.

In I 788, while acting as Minister in France but still a farmer at heart, he noted the unwieldy plough used there. Little seems to have escaped Jefferson, certainly not any inefficiency that might also impede the development of his own young country. His curiosity went to work. He wrote: "The awkward figure of their Mould board

\footnotetext{
${ }^{1}$ Somewhat expanded version of the tenth annual Jefferson Lecture, given in two parts (Washington, DC, and Boston, May 1981). This is a chapter in the forthcoming book, G. Holton, The Advancement of Science, and Its Burdens (Cambridge University Press, Fall 1986).
} 


\section{Gerald Holton}

leads one to consider what should be its form." He sketched how the wedge-shaped mouldboard of the plough should raise the soil so that it would topple properly by its own weight.

Three years later he described the progress he had made: "I have imagined and executed a Mould board which may be mathematically demonstrated to be perfect, as far as perfection depends on mathematical principles, and one great circumstance in its favour is that it may be made by the most bungling carpenter and cannot possibly vary a hair's breadth in its form but by gross negligence."

He made a model of it. To improve it further, in 1798, Jefferson, then vice-president of the United States, took from his shelf Emerson's Treatise on Fluxions, his old college book on the calculus, and re-derived the shape of the mouldboard and ploughshare that would offer least resistance to the soil. In 1805 , while President, Jefferson made yet another model, writing to a friend, "it took half a day ... which I could not spare till very lately." He submitted it to the American Philosophical Society, and he made plans to have the ploughshare cast in iron for wide distribution. He was awarded a gold medal for it by the Society of Agriculture, and published a scientific paper on the design. By May I 808, Jefferson had read in the Memoirs of the French Agricultural Society of the Seine District that an improved plough existed in France. He arranged to have one sent to him, despite the embargo his administration was enforcing on France. By October of that year he had received a French dynamometer and made experiments on the resistance of the plough to show that his was better than the best in France. Last but not least, he advocated the horizontal or contour method of ploughing, "instead of straight furrows." This ecologically sound method, he wrote, "has really saved this hilly country. It was running off into the valleys with every rain, but by this process we now scarcely lose an ounce of soil."

Jefferson is indeed an exemplar of the whole linked sequence of responsible research in science and technology: a concern, at the initial stage, for a technical solution to a socially significant problem; the innovation using, where necessary, the application of mathematics; the experimental tests; the disclosure by publication; the further development with a view to mass production; and, most significantly, the demand that the invention be used to benefit both the people and the land. His was a coherent course of thought and action. 
Jefferson persuaded Congress to back the Lewis and Clark expedition as a venture with commercial potential; but to the Spanish authorities, through whose territory they were to pass, he described it as a purely scientific mission. That was shrewd, but also right. The mixture of both motivations was correct. Jefferson regarded the expedition as a scientific survey of the place to which the nation's destiny was likely to lead. This dual-purpose style of research-basic scientific study that had no certain payoff in the short term but was targeted at an area of national importance-deserves a name. We would do justice to call it the "Jeffersonian Research Program."

My intention is not to paint Jefferson as a scientist. On the contrary, my main point is that he and others of his period, while unique in history as political thinkers, were typical of their time in that they considered it as natural to share in the current scientific world picture as in the classics of literature, philosophy, and statecraft.

If we turn our attention to this century's intellectuals, we find a situation very different from the comfortable incorporation of science into the world view that characterized the most prominent of the eighteenth-century models. At some point in the course of history, the intellectual pattern of our civilization changed. I must develop this point now, not because of a nostalgic longing for a return to eighteenth-century euphoric hopes (voiced in Voltaire's projection that "reason and industry will progress more and more, that the useful arts will be improved, that all the evils that have afflicted man ... will gradually disappear"); not because a current mutual incomprehension impairs discourse in the Common Rooms of some English colleges; but for a far more important reason-because we are witnessing a disjunction in the political and social life of the nation that curtails a main legacy of Jefferson's America, namely, our power of self-government.

My first witness is appropriately the writer, literary critic, and historian, Lionel Trilling, who in 1972 gave the first Jefferson Lecture, entitled "Mind in the Modern World." He began by reminding his audience of the loss of confidence in the power of mind, a confidence that had been characteristic of Jefferson's time. 
The old credo was that "if mind were cleared of its inherited illusions and prejudices, ... what has long been accepted as the inevitable rule of harsh necessity, might be overthrown, and mankind will achieve a felicity which was its immemorial dream and its clear evolutionary destiny." That was once true. But Trilling thought the title of the last book by H.G. Wells was a more appropriate summary of our present condition: Mind at the End of its Tether. Trilling pointed to two causes for the weakening of what had been a master belief for Jefferson and his time. One reason was our diminishing awareness of the past, what he called our "disaffection from history." But if the loss of history in our time has been, in a sense, self-inflicted and voluntary, such was not the case for the second, equally disorienting disability. For, Trilling continued, "the old humanistic faith conceived science, together with mathematics, to be almost as readily accessible to understanding and interest as literature and history." Jefferson, of course, could take that for granted; but this faith has been lost. Science, in our day, Trilling explained, "lies beyond the intellectual grasp of most men.... Its operative conceptions are alien to the mass of educated persons. They generate no cosmic speculations, they do not engage emotion or challenge imagination. Our poets are indifferent to them."

Having despaired of the hope Wordsworth expressed in the I $802 / 1805$ preface to the Lyrical Ballads, that the remotest discoveries of the scientists "will be as proper objects of the Poet's art as any upon which can be employed" if these things "shall be familiar to us," Trilling added a paragraph that captures the anguish of the modern intellectual, to whom nothing is more devastating than the irredeemable remoteness of a whole continent of fundamental knowledge:

This exclusion of most of us from the mode of thought which is habitually said to be the characteristic achievement of the modern age is bound to be experienced as a wound given to our intellectual self-esteem. About this humiliation, we all agree to be silent; but can we doubt that it has its consequences, that it introduces into the life of the mind a significant element of dubiety and alienation which must be taken into account in any estimate that is being made of the present fortunes of mind?

Trilling's chillingly accurate assessment has implications far beyond the concerns of a few academics. It would be a great error to dismiss 
it as the parochial anguish of intellectuals, unmindful of the dangers in the real world, a world where over half a billion people cower at the edge of starvation; where some fifty thousand nuclear warheads stand ready; where numerous states subjugate their people under totalitarian rule; and where even the majority of citizens in our democracy regularly fails to exercise its right to select who will govern. On the contrary, there is a direct link between those problems and Trilling's observation. As he noted at the end of his lecture, "this falling off [of the confidence of the power of mind] must be felt as a diminution of national possibility, as a lessening of the social hope. ... Mind at the present time draws back from its own freedom and power."

Trilling reveals both the intellectual and the political consequences of being denied knowledge without which some of our best thinkers cannot be sure they have a proper hold on the world. This sense of impotence in the face of the social and political decisions being made for us in this scientific age mirrors a fact that has even been documented in opinion polls: It used to be the case that the more educated the individual, the more he approved of science. Distrust was greatest among the least educated. Now there has been a complete reversal; the distrust is least among the most naive. From among the others we are beginning to hear the sentiment with which Bertold Brecht ended his play, The Life of Galileo: "In time you may discover all there is to discover-but your progress will only be progress away from mankind. The gulf between you and the people will become so great that one fine day you will cry out in jubilation over a new achievement-and be greeted by a cry of universal horror." William Faulkner, in his acceptance speech for the Nobel Prize, said simply: "There are no longer problems of the spirit. There is only the question: When will I be blown up?"

I have been pointing to a polarization that is pitting two groups, once allies, against each other: one, chiefly scientists and their followers, including technology enthusiasts, is cheered by the promise of ever greater scientific advances; the other is depressed and fearful in the wake of these very advances. How did this separation come about? 


\section{Gerald Holton}

We must look first into the intellectual machinery of scientific advance itself, to see what is causing these antipodal trends. Is there one common reason for both the euphoria and the despondency? How can an activity be seen as the isolated, esoteric pursuit of a few souls engaged in rapturous contemplation, and also as the dominant, perhaps uncontrollable force directing the very course of society? What is there about modern science that makes it so successful in the hands of relatively few, and so difficult or ominous for the rest?

A key to the answer will be to see that the progress of science and of science-based technology follows a pattern that is built in, and rather different from the progress of other activities. This order conflicts with the layman's impressions, produced by the daily stream of cheerful announcements of new findings and new products, emanating from university laboratories and technology-based industry. Their sheer quantity and lack of coherence must be as disorienting to the average person as the cacophony of events that buffeted Tolstoy's Pierre while he stumbled through Napoleon's battlefield. But despite their appearance of randomness, scientific and technical advances reflect a development akin to tree-like growth, a motion with two components: one vertical, toward a higher, more abstract state of scientific specialty; the second horizontal, branching toward the sides, where applications and repercussions radiate into other fields, from engineering to literature. This two-dimensional unfolding can be traced over history. Some components of the development indicate a tendency toward discernible goals-more so for the physical sciences, to which I shall necessarily restrict my specific examples, and less so for some of the other sciences, although in this respect they are all qualitatively similar. We shall find that the model of tree-like growth helps us understand the two main benefits of the advancement of science, and also the two main burdens.

First, consider the order associated with the upward thrust of science. It is motivated by a constant search for unities and simplicities behind nature's spectacle of variety, a reaching for ever higher, more general conceptions that allow one to see common features among the phenomena. I must insert here a disclaimer: Like all who have 
struggled with this question, I find it utterly mysterious that this search should be so successful-why, for example, the mathematical equation that applies to acoustic waves should be applicable again and again in widely different contexts, from the spreading of temperature profiles to the motion of elementary particles; or how ideas developed in the study of macroscopic phenomena such as superconductivity should turn out to be well adapted to deal with submicroscopic problems concerning the structure of nuclei. I recall a physicist asking, "Why is quantum theory possible at all? Why should a theory which you can write down essentially on one page apply correctly to untold billions of individual cases?" It is fitting to recall Albert Einstein's confession in his letter to Maurice Solovine concerning "the high degree of order in the objective world": "One has no justification to expect it a priori. Here lies the sense of 'wonder' which increases ever more with the development of knowledge."

Leaving aside the incomprehensible roots of its success, we do know what stimulates the search for unities and simplicities at ever higher levels of abstraction. While it takes seemingly different forms in different sciences, the upward thrust has been motivated in the physical sciences by the frank desire for "the complete [intellectual] mastery of the world of sensations." With these words, Max Planck, inventor of the early quantum ideas and author of the book Where is Science Going? (1932), answered the question posed by his title. That aim-reaching for omniscience about the world accessible to positive science, and hence for a complete scientific world picture-and the way to attain it, might be called the "Newtonian Program," because Newton, while not the first or last to embrace it, adhered so explicitly to it.

In the Preface to the Principia, Newton described his aim and procedure: The observable phenomena (e.g., the fall of objects to earth; some celestial motions) led him to postulate the existence of one general force of gravity by which all bodies attract one another, and from this he was able to deduce in detail "the motion of the planets, the comets, the moon, and the seas." But no sooner had he acknowledged this stupendous achievement than he added, with a hint of his deep disappointment: "I wish we could derive the rest of the phenomena of Nature by the same kind of reasoning from mechanical principles." These would include optics, chemistry, the 


\section{Gerald Holton}

operation of the human senses. There was the Holy Grail: the mastery of the whole world of experience, by subsuming it ultimately under one unified theoretical structure. Einstein similarly taught that "the noblest aim of science" was the attempt to grasp the "totality of empirical facts," leaving out not "a single datum of experience." Newton hoped even to go beyond that, to an understanding of the Godhead itself, as well as to the laws of social behavior. As he wrote in the Opticks: "And if natural Philosophy in all its Parts, by pursuing this Method, shall at length be perfected, the Bounds of Moral Philosophy will also be enlarged. For so far as we can know by natural Philosophy what is the first Cause, what Power he has over us, and what Benefits we receive from him, so far our Duty toward him, as well as that toward one another, will appear to us by the light of Nature."

Even without this additional aim, and similar ones proposed by the physiocrats of the eighteenth century and the technocrats of the twentieth, the ambition of the scientists' Newtonian Program is breathtaking. To understand better its dynamics, consider the pursuit of the Newtonian Program in terms of a simple diagram. Imagine a horizontal plane on which each point corresponds to a datum of experience, an observation, or a sensation. For example, in the left corner of this plane are points that represent observations of regular planetary motions, from Hipparchus to Tycho Brahe and onward. Next to it, to the right, are points representing the trajectory of projectiles and the falling of an apple; the data of motions of comets; the motions of the moon; the behavior of the tides; the shape of our spinning earth; the variation observed in the time kept by pendulum clocks at different parts of the globe; the propagation of sound and motion in fluids generally. Further toward the right side of this vast plane of experience are the data obtained from various phenomena of optics, from rainbows to diffraction. Beyond that is the curious behavior of charged amber, of currents, magnets, chemical reactions, and so on: the whole accumulation of the "facts" of nature that, at first glance, have little in common with one another.

One way to understand what I have called the Newtonian Program is to see what Newton did with this material. Observation of the phenomena at the left side of the plane led him to propose the existence of a universal force of gravity that diminishes with the square of the distance between bodies. To this postulated force 
Newton added what he called the three "axioms or laws of motion," some definitions (of mass, momentum, and the like), and a slew of mathematical propositions which nowadays could be greatly condensed. Together, the postulated force, the laws of motion, and the propositions formed Newton's axiom system, suspended above the plane of experience. The reason for this construction was to make logical deductions that were inherent in the axiom system, and to see whether these deductions coincided, or at least were not incompatible, with the known facts, i.e., the "points" on a good portion of the plane of experience below.

The Newtonian synthesis was an overwhelming success because it allowed a wealth of apparently disparate phenomena to be related in a very economical way, by seeing that they coincided with deductions from one simple, mechanical axiom system. Moreover, as new phenomena came into view, such as the motion of Uranus and Neptune, the rotation of the galaxies, and other previously uncharted extensions of the plane of experience, they too fell into place under the same "pyramid" formed by the initial axiom at the peak and the deductions radiating down from it.

The next major advance of that sort was Hans Christian Oersted's achievement in 1820 , showing that two other, similar pyramidal structures-one accounting for static and current electricity, and the other for the phenomena of magnetism-could be regarded as subsets within a larger and higher pyramid. Oersted found that a magnet needle could be deflected by an electric current, that currents surround themselves with magnetic lines of force. In this way, magnetism and electricity were fused into one conception, the first such unification of apparently separate forces of nature. Oersted's publication provoked an explosion of scientific work, including the discoveries of Ampère and Faraday. Technical applications followed quickly, starting with an electric telegraph.

Half a century later, the plane of experience had become crowded with many more discoveries, but the urge to achieve synthesis had succeeded again, and raised further the height of the axiom system embodied in the structure of physical theory. Maxwell was able to show that the phenomena involved in the propagation of light could be brought under the same roof with the unification of electricity and magnetism that Oersted had discovered. It was another achievement 


\section{6}

\section{Gerald Holton}

on the scale of Newton's, showing that phenomena that appeared diverse were really closely related.

Advances in the physical sciences have continued in this same style. The experiential horizontal plane has become more extended and the upward thrust remains powerful. One set of phenomena, such as the emission of beta rays in radioactivity, has been interpreted as the action of a force called the weak nuclear force that acts among leptons (of which the electron is an example). Another large set of nuclear phenomena is now understood in terms of the strong nuclear force acting among quarks.

Einstein had nourished the lifelong hope that a theory could be found to subsume the phenomena involving gravitation and those of electromagnetism under one greater axiom system, incorporating Newton's and Maxwell's pyramids into a yet higher pyramid, a unified field theory. It turned out, however, that this upward movement was achieved in a different way, by uniting the Maxwellian and the weak-force structures under one axiom system, characterized by the action of the "electro-weak" force.

Our attention is now focused on the next candidate for further unification, at yet a higher level of new axioms. The name "grand unified theory" has been coined for it. When the fog lifts, the two peaks symbolizing the electro-weak force and the strong force should turn out to have been just the lower portions of a still greater mountain range. If that is true, leptons and quarks would be related, and a lepton-quark conversion, indicated by the decay of protons, should be observable. This further widening of the plane of experience involves exacting experiments to bring into view phenomena that had not even been thought about previously. And beyond that? The attempt will surely be to subsume all four forcesgravity, the electromagnetic, the weak, and the strong force-in one theory, a tentative version of which is referred to simply as "supergravity."

In this schema of the Newtonian Program much has been left out, not least the intense analytic activity in the lower foothills without which these upward synthetic thrusts would not be possible. As in the building of the Rocky Mountains, a vast amount of energy has to be supplied from the base. Here it takes the form of painstaking experiments to test the flexibility and limits of provisional theories. Nor have I dwelt on a curious consequence of this mode of advance, 
namely, that it constantly cannibalizes earlier achievements, incorporating the useful parts within the newer setting. The labors of scientists are not really cumulative; rather the new growth makes the old invisible by absorbing it. This is, of course, one of the chief differences from the arts and literature, in which each work retains in principle its individual claim to respect from later practitioners or the public, and perhaps also maintains continued vitality as a source of new inspiration.

Despite its limits, the model I have proposed does illustrate that science, in the words of the philosopher W.V. Quine, is not an assemblage of "isolated bits of belief, but an interconnected system which is adjusted as a whole to the deliverances of experience." The schema also indicates why this audacious method of construction does not result in the Tower of Babel: it is at the bottom of the schema that the various languages are spoken, whereas at the top they all become one. In addition, it helps to understand the historic fact that science seems to follow what Alexandre Koyré called "an inherent and autonomous" development. Finally, this outline sketch may explain why the success of the enterprise can on occasion release high expectations and imperialistic ambitions. The physicist Leon Rosenfeld, writing about the I920s, reported: "It is difficult to imagine the enthusiasm, nay the presumptuousness, which filled our hearts in those days .... A friend of mine expressed his view of our future prospects: 'In a couple of years,' he said, 'we shall have cleared up electrodynamics; another couple of years for the nuclei, and physics will be finished. Then we shall turn to biology.' "'

A single-minded, optimistic spirit grips the community of scientists engaged in today's high-metabolism, high-stakes enterprise. They seem to be caught up in the promise that perhaps in our own lifetime we shall really know why electrons, protons, and neutrons exist; what the life cycle of the universe is, from the initial Big Bang to the final Big Crunch; and what the connecting links are between the various states of organized matter, from atoms to living things to societies. Few scientists doubt that the Newtonian Program can eventually be completed, and few could think of a better way to invest their lives than in that grand project. Measured by its own criteria, scientific research has never been of higher quality, or the prospects greater that the best is just over the horizon. 


\section{8}

\section{Gerald Holton}

One answer to the common, plaintive question "Where is science going?" is therefore the practical response of most scientists: If you give us the means, and a flow of spirited young people to assist us at the frontiers of inquiry, and if the sciences are allowed to follow their own manifest destinies, there is virtually no limit to their continued perfection. The haunting promise is that we may achieve a panoramic view of the whole physical world, one that will allow the mind's eye to obtain, at a single glance, a unified perception of all physical events, causes, and effects. In Einstein's words: "The confident belief that this ultimate goal ... may be reached, is the chief source of the passionate devotion of the researchers." Even if that great project proves endless, it now provides science with a purposeful drive toward a goal, a telos. Even though there are always many more "diversifiers" than "unifiers," the vision of the latter helps organize the smaller local tasks; it tides us over the inevitable periods of stagnation and failure; and it will continue to stimulate the community long after our current achievements have come to look small from the new heights.

In the exact sciences other than the physical ones, the upward thrust toward a more encompassing view has been organized on different lines and around other key conceptions. Such differences are of immense interest to the historian of science, but are not significant here, because what will concern us shortly, as one set of consequences of the mode of advance I have sketched, are the costs of this method of achieving a scientific world picture-and these costs are much the same for all scientific fields. Yet, before we turn to that, I must refer briefly to the second process in the unfolding of science, the outward movement to the right and left. Here we shall be concerned not with the building of higher conceptual structures in the pursuit of omniscience, but with the primarily instrumental aim of increasing human power through "mission-directed" research.

For the purpose of illustration, it will be useful to refer to a specific case, such as the targeted research project in 1946-48 that led to the transistor, and for which the 1956 Nobel Prize for Physics was awarded to John Bardeen, William Brittain, and William Shockley of 
the Bell Telephone Laboratories. Unlike the classic "pure" or "basic" research which generally starts and ends in the minds of scientists, this development quickly triggered a proliferating set of devices, from heart pace-makers to high-speed computers-devices that have begun to change civilization itself, including, indeed, how basic research can be done effectively in the sciences and in some areas of the humanities.

At the ceremony presenting the three Nobelists to the King of Sweden, E.G. Rudberg of the Royal Academy in Stockholm compared them to the "small party of ardent climbers" who have reached the "summit of Everest," even though they had started their assault from a high-altitude camp that "more than a generation of mountaineers had toiled to establish." Such an image applies to the Newtonian Program of autonomous, basic research, but it is not really appropriate for this case or others of the type. A historical study would quickly show that many factors essential to the achievement of these scientists were absent from the typical project we discussed earlier-most important, a mission orientation, embodied in the institutional policy of the Bell Laboratories, announced in 1945, to obtain "new knowledge that can be used in the development of completely new ... elements of communication systems." The pressure during World War II to develop rectifiers acting as crystal detectors for radar provided a strong impetus, as did an old hope of making amplifiers that avoid the power drain of vacuum tubes, and switching devices without the usual problems of corrosion and slow response. The work was "problem-focused"; it depended as much on the expectation of relatively short-term payoff as it did on the quantum physics of the I920s and I930s.

When the three scientists were later interviewed, they revealed that much of their success depended also on "extraneous factors," for example, the particular style of work of the laboratory-a pragmatic experimentalism nourished by the rather American mix of science, engineering, and improvisation-and on the mobility of young scientists seeking to train under skilled teachers. In short, the three who made it to the top of Everest were much helped by other mountaineers, by Sherpa porters, by supporting organizations near and far, and by a mandate for useful results.

The mission-directed style of research usually leads to both intended and unintended changes in current technology, engineering, 


\section{Gerald Holton}

medicine, or agriculture, and so affects the social matrix much faster than do the results of basic research. This penetration may be represented by a diffusion of effects from the realm of scientific concepts into the polity, a lateral outreach that is not a mere by-product but a chief aim of mission-directed research. In essence, the motivation here is instrumental. This style of work might be termed the "Baconian Program," for it was Francis Bacon who urged the use of science in the service of omnipotence, "the enlarging of the bounds of human empire, to the affecting of all things possible."

Whether the title is quite appropriate is unimportant. The significant fact is that in our time a remarkable symbiosis has established itself between the Newtonian and Baconian Programs. There have always been occasional cross influences-historians of science are still debating whether Galileo learned more from the workers in the Venetian shipyards, or they from him-but now these two approaches have come to interpenetrate each other thoroughly, just like two mechanical systems that exchange energy more rapidly and vigorously while they resonate with each other. The "pure" and the mission-oriented versions of research send their respective products back and forth, increasing their own rate of advance as they do sotightening their coupling further, and also blurring the distinction between them.

The marriage of science and technology is undoubtedly permanent and beneficial to each. The experimental side of science has become more technological (the sealing-wax-and-string era of laboratory work ended when World War II technology was declassified), and engineering depends increasingly on a scientific base. Indeed, the laboratory experiments that confirmed the theory of unification of the electro-weak force depended chiefly on products of modern electronic engineering. Conversely, the design of industrial products of biotechnology follows by only a few years or even months the latest results of basic research in genetics and molecular biology.

The first main consequence of the advancement of science in our time is one that we may be sure Jefferson himself would have been delighted to see. The accelerating process of unfolding has brought us 
to a fairly coherent overview of nature and the design and production of powerful technical devices, while a cybernetic process of positive feedback allows the continued, simultaneous escalation of scientific as well as engineering advance. Another consequence of this process, insufficiently noted, would perhaps have appealed to Jefferson even more. It is not merely a question of the commonplace observation that our physical burdens have lightened, farm life has been transformed, and medicine improved, but of the direct and indirect influence that the results and attitudes of scientific/technological advance have had in extending the very conceptions of human rights. Since Thomas Hobbes, to whom the essence of such rights was merely the freedom to eat and be eaten, moral and legal rights have increased greatly. Scientific findings in biology, anthropology, psychology, and other branches are largely responsible for making us certain, as Jefferson's time was not, of the essential homogeneity of the human race-a fact from which springs the entitlement to protection against discrimination. Biomedical advances have made it possible to respond to the clamor for access to medical care, and to support the right of women to assert choice in family planning. Such examples can be greatly extended.

D.D. Raphael has observed that the various twentieth-century declarations of human rights incorporate as necessities what, in previous centuries, would have been luxuries, and that material advance stimulated the continuous expansion of the definition of human needs. J.E.S. Fawcett, surveying the whole issue of protecting human rights, concluded that "fundamental to all effective methods of implementation of human rights" is the development of scientific rationality itself-“independent and objective fact-finding"-as well as the modern technology of rapid communication and publicity. One fact the discussions on modern theories of rights agree on is, in the words of C.B. Macpherson, that the "theory [of human rights] finds itself in need of development to meet changed conditions," and these changed conditions are to a large extent due to the influence of science and technology on the operations and values of modern society.

Increases in productivity, for example, have quite undermined old assumptions of permanent contentiousness and possessive individualism that were based on the notion of the inevitability of severe scarcities of resources. (One of the early, unexpected results of the 


\section{Gerald Holton}

spread of railways was that local famine became avoidable, and therefore intolerable.) The very increase in the number of charters and debates on human rights in our time may reflect the recognition that central portions of the Hobbes-Lockean "liberal-individualist" tradition, as well as the Rousseau-Marx "anti-bourgeois" traditions, are no longer relevant or sufficient, leaving us with the task of redefining, in the modern context of a technologically driven society, a workable framework for human rights that extends those derived from the Declaration of Independence.

I shall now turn to the two main consequences of the advancement and symbiosis of science/technology that are of a less happy kind: the new burdens. The first and most obvious of these is loss of contact. Despite popularization by the mass media, the concepts and methods of science have become largely inaccessible to all but its practitioners and a small circle of attentive onlookers. On the basis of an extensive anthropological study, Margaret Mead noted more than two decades ago that both school children and adults in our society had, over the previous fifty years, "come to feel that science is something deficient and alien, a discipline that they neither can nor care to understand." While Americans embrace with delight the products of technological industry, the conceptual base of their operations remains opaque to most, unlike the earlier tools and devices that were relatively transparent and comprehensible.

The intellectual brilliance of our sciences, the ingenuity of our technologies, may be characteristic of our culture, but from the point of view of the public and most intellectuals, the thought processes and operations of both have moved behind a dark curtain. There they have taken on a new form of autonomy-isolated from the active participation or real intellectual contact of all but the highly trained. Contrary to eighteenth-century expectations, the scientists are losing what should be their most discerning audience, their wisest and most humane critics.

This burden is, ironically, caused by the very success of the method of scientific/technical advance. As the process of building a unified scientific world view proceeded, as the conceptual structure grew 
more elevated, the chains between the axioms at the top and the empirical base at the bottom had to extend further. The logical structure reaching down from the axioms became more formal and parsimonious; the bridge to ordinary intuitions and to the rationality of every-day thinking was first stretched, and then was lost or became an actual handicap. While in Jefferson's day it was possible for those in his circle to value and comprehend much of the science not only of Newton's time but of their own, this ceased to be the case for interested onlookers a century or so ago. By now, the instructive metaphor is essentially unavailable, and the barriers of communication are virtually insurmountable even for the interested nonscientist-despite Einstein's warning: "I can think of nothing more objectionable than the idea of science [only] for scientists. It is almost as bad as art for the artists, and religion for the priests."

As the plane of experience expands through the use of specialized or high-technology observational devices, the public progressively loses access to the phenomena of nature. The connection between phenomena and theory, the theory itself, and the way it is constructed, confirmed, and elaborated are, and have to be, fully controlled by the scientific community, and understanding them comes only with long immersion. We can see more clearly one of the chief causes of Trilling's perception. Precisely as science progresses toward its declared goal, and as the rate of its new triumphs increases, the larger yawns the unnegotiated intellectual separation from those standing on the sidelines-all those who feel the shame and sorrow of being excluded "from the mode of thought which is habitually said to be the characteristic achievement of the modern age."

I must now turn to the second cost, which is also a by-product of the dazzling advancement of the modern science-cum-technology complex. It is a cost not to the intellectual power and integrity of our cultural trustees, of which Trilling spoke, but to the political effectiveness of our citizenry. The source of this burden lies chiefly in the fact that the metabolism of the science/technology complex has progressively increased since Jefferson's days. As it continues to do 


\section{Gerald Holton}

so, it enlarges the scale of technological intervention in our lives at the same time as it inhibits our opportunity to evaluate and respond to the ethical and value impacts of these interventions. The old (and sometimes blind) faith in the benign efficacy of technological progress has been waning, even yielding to its very opposite-the fear of an autonomous technology, and the rise of an ideology of limits.

The relative modernity of this concern can be illustrated by studying the outcome of the seemingly humble scientific discovery made over a century and a half ago, in October I 83 I. When Michael Faraday in London put his hand on a copper disk, and made it rotate between the poles of a magnet, a steady electric current was induced in the disk. He had discovered (or invented) the electric generator, or dynamo. The simple gadget was a by-product of Faraday's lifelong search for his true and quite "Newtonian" goal-to find through the study of diverse scientific phenomena the unity of all nature's forces. Faraday's dynamo took the energy his hand gave to the disk, and made that mechanical energy reappear as electrical energy which could be drawn off in the wires connected to the disk.

It might have remained a scientific curiosity, and a mirror image of the motor effect Faraday had found eleven years earlier when pursuing Oersted's findings, but Faraday's new dynamo (and the version Joseph Henry invented at almost the same time) was a source of electricity more effective and cheaper than the battery that Volta had discovered in 1800 ; it was soon redesigned to use mechanical energy from any source-wind, water, steam, coal, wood, gas, or oil-and to issue forth electrical energy for immediate transmission to distant points, as far as cables could reach. There, motors reversed the process, yielding back mechanical energy to do work; or resistors could convert the electrical energy to heat and light.

The physics involved is not sophisticated, but the effect on society was. At last, the source of energy did not have to be in the same place as the ultimate user, a crucial difference from the steam engine, burdened down by its fire box, boiler, and fuel. The dynamo could be anywhere and produce its effect with high efficiency at a great distance; its action was almost instantaneous, its capacity in principle virtually limitless, the raw material used for the prime mover relatively cheap, and the sanctions against disposing of the effluents practically absent. 
As a result, the total system was immensely potent, indeed irresistible. The dynamo, in hundreds of forms and uses, became the keystone that completed the industrial revolution and the modernization of day-to-day life. The modern city could not have risen without the development of the dynamo, for on it depends essential transportation such as elevators and subways, and all electrical lighting, signaling, communication, and control. Life in the factory, in the workshop, and eventually on the farm was transformed by the new generators, as were industrial processes; the electro-chemical industry, which had initially not been considered a beneficiary when the great Niagara Falls power plant was built, was by the turn of the century using more electrical power than lighting and motors together.

What interests us here is that the introduction of electric power into society and the landscape, while not without difficulties, was a remarkable success. One reason was simply that enough time had elapsed to allow a degree of intellectual and political accommodation. The design of commercially viable generators took nearly fifty years after Faraday's first model, and brought together a great variety of interests-scientific, technical, financial, managerial-in many countries. The various problems of "electrification" engaged citizens at every level, from Parliament and Congress to individual towns and villages. The system that finally evolved was a compromise between divergent interests and alternatives that had been widely debated and considered at length.

Such public involvement is just what is becoming less and less possible as the rate increases at which science-based technology is injected into the life of the nation. Thus the rapid initial deployment in the United States of nuclear reactors for power generation turned out to be a disaster for that industry itself. Concern about the long-range consequences has also been raised by the rapid computerization of the work place, by the introduction of the robotic factory, and by the vast new weapons systems now on the drawing board and in production. These and similar decisions no longer grow out of an organic adaptation among all the relevant interests, a process of evolution in which sufficient time can elapse to allow technical details to be learned and open debate to take place among an informed citizenry. According to a recent estimate, nearly half the Bills that come before the U.S. Congress have a substantial 


\section{Gerald Holton}

science/technology component. Yet few in Congress or on its staff have, or can have, the training and background to be really familiar with the problems. We are reminded of Lord Snow's well-known prediction that in such a climate the decision-making process may be usurped by the " scientific overlords," and of Eisenhower's Farewell Address (January I96I), warning not only of "the acquisition of unwarranted influence ... by the military-industrial complex," but also of the "danger that public policy could itself become the captive of a scientific-technological elite."

In a recent essay, "Coping with Technology through the Legal Process," David L. Bazelon, Chief Judge of the U.S. Court of Appeals for the District of Columbia Circuit, wrote that "some two-thirds of the D.C. Circuit's caseload now involves review of action by federal administrative agencies, and more and more of such cases relate to matters on the frontiers of technology." In discussing how "society can come to terms with science and learn to cope with technological process," Judge Bazelon concentrates on the central issue that virtually every technological innovation introduced to solve a societal difficulty will also have unwanted consequences-hence will require some painful value choices and difficult policy decisions to be made.

Scientists and engineers do have a role to play, but it is a limited one; for as expert witnesses or advisers they are likely to disagree about some basic facts in the case, and to disagree all the more about value-laden inferences from these facts. These diverse opinions, together with all relevant information, must be put on the table-not in a courtroom, where the judge is unlikely to have even a "speaking familiarity" with the issues, but in a public setting: before the decisionmakers directly responsible to the citizenry; in forums that allow public input and participation; before regulatory agencies; and above all before elected legislatures, which, in a democracy, are precisely the bodies intended to make the value choices. Judge Bazelon concludes that this may be a far slower and more cumbersome process than the tempting alternative, where the decision is made by a very few outside the public arena; but that alternative is exactly what must be avoided. He quotes John Stuart Mill:

Even if the received opinion be not only true, but the whole truth; unless it is suffered to be, and actually is, vigorously and earnestly contested, it will, 
by most of those who receive it, be held in the manner of a prejudice, with little comprehension or feeling of its rational grounds.

We come here to Thomas Jefferson's lifelong insistence, and the very kernel of his teachings-that citizens are the only safe guardians of their liberty and pursuit of happiness. Not even with the best will in the world can the judges and the courts, the legislators in their ill-attended sessions, or the scientists, engineers, and other specialists advising decision-makers play this role for them. All these together are only part of the framework within which citizens can make their franchise effective. To do that, however, requires an adequate level of knowledge, which must be achieved through a "systematic plan of general education" in schools and colleges and later through continued self-study. To James Madison he wrote in December I787, while discussing the proposed constitution: "Above all things I hope the education of the common people will be attended to; convinced that on their good we may rely with the most security for the preservation of a due degree of liberty."

For those who are able, Jefferson repeatedly proposed-for the same ultimate purpose-courses of study that were not far from his own at William and Mary, and that put to shame much of what now passes for a typical curriculum. To one of his correspondents (William Green Munford, I799), who asked about a good reading list for mathematics, Jefferson recommended some Euclid, some Archimedes, trigonometry ("There is scarcely a day in which [every person] will not resort to it for some of the purposes of common life"), the science of calculation through cube roots, quadratic equations, logarithms, and "fluxions" [calculus] as an "added luxury." He continued, "There are other branches of science, however, worth the attention of every man" and necessary for "our character as well as comfort": "Astronomy, botany, chemistry, natural philosophy, natural history, anatomy, [at least] to possess their general principles and outlines, so that we may be able to amuse ourselves and inform ourselves further in any of them as we proceed through life and have occasion for them." His use of the term "science" shows that he had in mind the balance of the major branches of 


\section{Gerald Holton}

knowledge; in addressing Joseph Priestley (in January I 800) his list of sciences includes "Politics, Commerce, History, Ethics, Law, Arts, Finearts."

Not for Jefferson the image of the mind at the end of its tether! On the contrary, he confesses freely to believe, with Condorcet, that man's "mind is perfectible to a degree of which we cannot as yet form any conception." To think otherwise, to harbor the "cowardly idea" that the human mind is "incapable of further advances," was to embrace a doctrine that fitted well the purposes of the "present despots of the earth, and their friends." For in Jefferson's view, the main objective, "the freedom of the human mind," is secured only if the mind is educated or engaged in self-improvement. It is in this sense that (in a letter of I795 to François D'Ivernois) he identified freedom as "the first-born daughter of science"; conversely, as he told Joseph Priestley in I810, "ignorance puts everything into the hands of power and priestcraft."

Thus the primary purpose of improving knowledge and understanding was, for Jefferson, not to produce a cadre of scientists and literati; not to design better "protection against foreign power"; not even its necessity "for our character as well as comfort," important as all these were. The foremost purpose, as he put it, lay in the importance of knowledge and informed debate "to the preservation of our republican government."

We would do well to remind ourselves today of Jefferson's threefold preoccupation: that the highest good is the exercise by individuals of their natural rights; that the inevitable excesses of power, if unchecked, lead to oppressive regimes; and that the chief safeguard against this course of degeneracy is the wide dissemination of liberal education. He stated this credo most clearly in his courageous "Bill for the More General Diffusion of Knowledge" (I778). It begins with a manifesto that deserves to be inscribed over the doors of our schools:

Experience has shown, that even under the best forms [of government], those entrusted with power have, in time, and by slow operations, perverted it into tyranny; and it is believed that the most effectual means of preventing this would be to illuminate, as far as practicable, the minds of the people at large, and more especially to give them knowledge of those facts, which history exhibiteth, that, possessed thereby of the experience of other ages and countries, they may be enabled to know ambition under all its shapes, 
and prompt to exert their natural powers to defeat its purposes .... Whence it becomes expedient for promoting the publick happiness that those persons, whom nature hath endowed with genius and virtue, should be rendered by liberal education worthy to receive, and to be able to guard the sacred deposit of the rights and liberties of their fellow citizens ....

One may quarrel about the details of a realistic education that could safeguard the mind's freedom and effectiveness, now that the nation has grown vastly from the three million inhabitants of Jefferson's predominantly rural, isolated America. Even allowing for the sophistication of modern knowledge, the complexities of modern problems, and the potentially more calamitous results of bad decisions, one may consider his curriculum "worthy of the attention of every man" to be unreasonably demanding. However, national policy does respond to its leaders' expectations.

Yet, the evidence points to a catastrophic reduction of the normal expectation and preparation in the education of our future citizens. The findings are chilling in every field, and those for the sciences merely typical. A carefully assembled study by the National Academy of Sciences for the President in I 980 concluded that the current trend is a tailspin "toward virtual scientific and technological illiteracy." Moreover, as if to thumb its nose at Fate, the next administration began in I98I to phase out federal support for science education at the college and precollege level-the only industrial country to do so.

The need for an informed and confident citizenry to assure that the processes of democracy continue to work has not diminished. The very opposite is the case. In addition to adopting the role of alert watchdog of national and local policy, we all bear the burden of making personal decisions whose soundness depends on our ability at least to ask questions about their technical context. Everyone is caught in this vortex: the engineer who discovers in mid-career that, while he knows how to design a new plant, as he was trained to, he now has to learn how to evaluate the ecological impacts; the administrator forced to deal with ambiguous scientific data or probabilistic risk-benefit analyses in some economic dispute; the board chairman as well as the greenest worker, when the old office is turned over to electronic machinery and the shop floor is automated; parents having to decide what processed food to feed their child; the doctor or clergyman when faced with ethical problems raised by new technologies that allow us to initiate, prevent, or end a life at will. 
If one has no base on which to formulate probing questions, can one actually give informed consent to planned surgery? How can jobs be designed for people who are not skilled or numerate? How is the issue of privacy affected when bank accounts are absorbed into the electronic fund transfer system? How does one react in an informed way-that is neither hysterical nor techno-enthusiastic-to a plan for siting a power plant nearby, whether nuclear or not?

There are a few inspiring examples of collaborations between scientists and the public, bringing enlightened solutions to complex technical problems that face the nation. One is the cessation in the early 1960 of of nuclear weapons testing in the atmosphere, chiefly as the result of a major educational campaign mounted by scientists and others concerned about the health dangers of radioactive fallout. (One congressman was reported to say: "When parents wrote me that Strontium-90 from fallout was getting into their children's teeth and bones, I knew I had to pay attention: they were spelling Strontium correctly.") A second, more recent example was the debate about the safety of laboratory experimentation with recombinant DNA, which was finally resolved in a manner satisfactory to practically all involved. Both these and a few other such instances had in common patient educational efforts and protracted debate among scientists and groups of laymen.

For just that reason, these are the exceptions. As a rule, there is not enough time or talent to build up successful communication between groups of concerned scientists and voters to help form a national decision agreeable to each. Technical details are (or at least seem) so complex to the layman, and their initial base of knowledge is so frail, that serious effort is discouraged. This is most evident today in the difficulty of conducting a meaningful debate on weapons policy. The arms race is full of absurdities, not the least being that it is a grotesque offspring of a perverse coupling, in each country, between international, unifying science and parochial, aggressive nationalism. The worst of these absurdities is that the arms race, with all its costs and dangers, has long since ceased to be reasonable on grounds of national security. Larger and more expensive systems are being designed and deployed that at best will have only marginal value in terms of security, and are far more likely to divert resources and destabilize the fragile geopolitical equilibrium. 
The purely technical facts, widely accepted among competent evaluators and accessible with some effort to any seriously interested citizen, point to the wisdom of calling a halt, especially to the accumulation of nuclear arms. Indeed, beyond one hundred or so weapons on each side, deterrence is saturated. What drives the race now, in both superpowers, are political and perceptual rather than technical factors, perceptions of power rather than physical realities. It would be a triumph if this fact could be made clear to the citizens of the nuclear powers. One of the main obstacles is surely the widespread inability or unwillingness to handle key concepts of a technical kind. Even political leaders with the right intentions and good scientific advice have been disabled by the fear of backlash. We now learn from those close to President Kennedy that in July 1963 he felt unable to follow the recommendation of his scientific-technical civilian advisers to sign an agreement on a complete nuclear weapons test ban with the Soviets, including an end to tests of significant size not only in the air, sea, and outer space, but also underground. Such a comprehensive agreement-which Eisenhower had also considered essential-could have changed world history by containing the nuclear weapons race at that point, and incidentally would have preserved the technological advantage the United States had then. The Soviets, in a notable departure from past positions, were prepared to accept two or three annual inspections on their soil for monitoring suspected cheating. Technically, this was sufficient, for it provided a good probability of discovering really dangerous new developments (involving a long series of tests, rather than one or two that might escape notice). Moreover, better seismographic monitoring at a distance without on-site inspection could be, and soon was, achieved to provide further deterrence against breaking the offered agreement.

Yet, Kennedy did not dare ask Congress for such a treaty. He felt, probably correctly, that despite all its advantages, the proposal would be rejected because it was based on concepts of probability-one of the notorious blanks in modern education. As the ensuing debate showed, a majority of citizens, unfamiliar with the rudiments of probability, required a higher (and, to the Soviets, unacceptable) number of on-site inspections, in order to feel that they knew "for certain"-even though the only certainty was that the lack of a comprehensive ban would assure the dangerous and costly continu- 


\section{IO2 Gerald Holton}

ation of the nuclear menace, the inevitable increase in the size, variety, and proliferation of those weapons, and the introduction of additional systems.

The Academy report I quoted earlier warned that "important national decisions involving scientific knowledge will be made increasingly on the basis of ignorance and misunderstanding." As the divergence widens between those who make policy and citizens who lack the knowledge to assess their proper interests, the threat increases: the nation is in danger of being torn in two. The wound already felt by sensitive humanists such as Trilling must sooner or later become a traumatic separation-the most ironic cost of the advance of the modern science/engineering complex. On one side of the gulf will be a relatively small, technically trained elite, consisting chiefly of scientists, engineers, technicians, and other highly skilled individuals, amounting to a few percent of the population. As an increasing proportion of major decisions have a scientific/technical component, they will supply the new potentials as well as advice on how to direct and use them. On the other side will be the huge majority of the people, without sufficient language, tools, or methods to reason or to argue with the experts, to check on the options they present, or to counter either their technical enthusiasms or their doomsday warnings. That majority will effectively place itself in the hands of the elite, perhaps sinking quietly into the comforts and amusements which technology has helped provide. Some cynics may even welcome such a state of affairs, for the ignorant tend to be easier to govern and to divert into militant philistinism.

These new illiterates will be slaves with respect to the key issue of self-governance, a possibility expressed by Cardinal Newman in the Idea of a University: "Not to know the relative disposition of things is the state of slaves." For them, in a grotesque reversal of the Enlightenment dream, the answer to the question, "Where is the modern advance of knowledge and power taking us?" will be, "Into a new slavery."

I have chosen that word advisedly. The historian, John Hope Franklin, in his 1976 Jefferson Lecture, reminded his audience of the conditions that helped keep slavery intact in early America. One of these was the denial in the eighteenth century that slaves could reason. Jefferson himself once expressed the opinion, although "hazarded with great diffidence," that among the slaves "one could 
scarcely be found capable of ... comprehending the investigation of Euclid." That was his touchstone. For many eighteenth-century thinkers, slaves would not come under the Law of Nature, which, as John Locke had said, is Reason, and from that law Locke derived the natural rights. In Locke's Second Treatise on Government, which Jefferson claimed to know almost by heart as he drafted the Declaration "without the help of books," Locke taught that man has not the liberty to renounce liberty, to renounce being a naturally free being, and to make himself a slave of others. To be a slave, in Locke's words, is to be "degraded from the common state of rational creatures," hence a species apart.

The slaves of the eighteenth century were not given the choice, were not responsible for their shackles. Our new slaves will be different in this respect; for drawing one's mind back from one's own freedom and powers amounts to a willful self-estrangement, a voluntary renunciation of self-government on the hard issues that determine the fate of a people.

I have outlined the long-range consequences of the intellectual and political costs facing us, largely by-products of the accelerating advancement of knowledge against the background of citizens unable to understand enough to take command of their own destiny. It is a stark picture, and the practical obstacles for the more obvious remedies are formidable. Yet I would not have addressed this issue, had I thought the present course uncorrectable. I have referred to a few of the tools for establishing a new equilibrium, ranging from educational programs to the relocation of at least some basic research into areas where there is some motivation to pursue more Jeffersonian Research Programs, alongside the current Newtonian and Baconian ones. There are others; the nation does not lack good ideas. Rather, it is the scale and seriousness of our current efforts that are inadequate. An assertion of national will and leadership is sorely needed to learn how to live in the modern age while preserving one's dignity and self-governance.

The idea of the "Learning Society" has been the mainspring of every period of civilization, from Athens and the Renaissance to the 


\section{IO4 Gerald Holton}

founding of our republic; it must now be broadened to encompass not only Jefferson's person of "genius and virtue," but the whole population. In this way, the hope of the Enlightenment will not be dissipated, and the energies characterizing both the people and contemporary scholarly and scientific advance will be directed to the benefit of each.

In I 8I 2, Jefferson, then seventy, replied from Monticello to his friend John Adams. Downcast at that dark point in history, he wrote:

As for France and England, with all their preeminence in science, one is the den of robbers, and the other of pirates. And if science produces no better fruits than tyranny, murder, rapine and destitution of national morality, I would rather wish our country to be ignorant, honest and estimable as our neighbouring savages are.

But wither is senile garrulity leading me? Into politics, of which I have taken final leave. I think little of them, and say less. I have given up newspapers in exchange for Tacitus and Thucydides, for Newton and Euclid; and I find myself much the happier.

But Jefferson's native optimism prevails all the same, an optimism we can share if we do not neglect the tasks before us. He told John Adams:

[Your letter] carries me back to the times when, beset with difficulties, we were fellow laborers ..., struggling for what is most valuable to man-his right of self-government .... We rode through the storm with heart in hand, and made a happy port. Still we do not expect to be without rubs and difficulties; and we have had them .... And so we have gone on, and so we shall go on, puzzled and prospering beyond example in the history of man. And I do believe we shall continue to grow, to multiply and prosper, until we exhibit an association, powerful, wise and happy, beyond what has yet been seen by man. 